\title{
Effects of Extracellular Calcium and Other Divalent Cations on Mechanical Response of Frog Skeletal Muscle
}

\author{
Junna Hatae and Hiroshi Kawata \\ Department of Physiology, School of Medicine, Fukuoka University, \\ Jonan-ku, Fukuoka, 814-01 Japan
}

\begin{abstract}
In order to investigate the mechanism by which elevated extracellular $\mathrm{Ca}$ ions decrease twitch and tetanus tension in frog skeletal muscle we made mechanical and electrophysiological measurements on single fibers or small bundles from twitch muscles. High concentration of Ca caused a hyperpolarization and an increase in the duration of action potential. The mechanical threshold, estimated by using the strengthduration curve, was shifted upward by adding $\mathrm{Ca}$ ions. These effects were fully reversible. Steady state twitch tension was slightly increased by replacing $\mathrm{Mg}$ and $\mathrm{Ni}$ with $\mathrm{Ca}$ and decreased by elevating their concentrations, although $\mathrm{Ba}$ resulted in a marked twitch augmentation and a positive correlation with the ion concentration. By contrast, the strengthduration curve was shifted upward by $\mathrm{Ni}$ while $\mathrm{Mg}$ and $\mathrm{Ba}$ showed no shift. These evidences point to a failure of the early step of excitationcontraction coupling, including the T-membrane depolarization, as the primary mechanism of action of high concentration of $\mathrm{Ca}, \mathrm{Mg}$, and $\mathrm{Ni}$ ions, whereas $\mathrm{Ba}$ ion has an additional intracellular potentiating effect.
\end{abstract}

Key words: frog skeletal muscle, divalent cations, twitch tension, tetanus, contraction threshold.

There is little doubt that the inward conduction of excitation along the transverse tubular system (T-system) in skeletal muscle involves a $\mathrm{Na}$-dependent regenerative process similar to the conduction of the action potential along the surface membrane (BASTIAN and NAKAJIMA, 1974; BeZanilla et al., 1972; CapUto and Dipolo, 1973; Costantin, 1970, 1975). Depolarization of the T-system leads to release of $\mathrm{Ca}$ from the sarcoplasmic reticulum, but the link between depolarization of the muscle membrane and $\mathrm{Ca}$ release is not known. Thus the depolarization of the T-membrane can be considered the first crucial step for the electromechanical coupling.

Received for publication September 9, 1988 
The aim of the present study is to clarify the effects of divalent cations such as $\mathrm{Ca}, \mathrm{Ba}, \mathrm{Mg}$, and $\mathrm{Ni}$ on the twitch and tetanus and to observe the influences of these cations on the mechanical threshold. The measurements of the mechanical threshold have been done in various ways, for example, by using the $\mathrm{K}$ contracture (Hodgkin and Horowicz, 1960; Lüttgau, 1963; Frankenhaeuser and LÄNNERgren, 1967; LÜTtgau and SPIECKER, 1979; CotA and StEFANI, 1981; GrAF and SCHATZMAnN, 1984) or under the voltage clamp (CAPUto and Bolanõs, 1979; Potreau and Raymond, 1980). The determination of the mechanical threshold has also been made by intracellular current application in $\mathrm{Na}$-free medium (DÖRRSCHEIDT-KÄFER, 1976). In the present study we adopted an extracellular polarization method for determination of the strength-duration relation, an expression for mechanical threshold, which allowed induction of a local contraction under rather physiological condition. In this paper we show that the divalent cations affect the contractile response by changing the mechanical threshold. A part of the results have been reported in a preliminary form (HATAE and KAWATA, 1985).

\section{MATERIALS AND METHODS}

The preparation used was the semitendinosus muscles of the frog (Rana japonica). Single fibers or small bundles consisting of a few fibers were mounted in a chamber $(0.5 \mathrm{ml})$ and continuously superfused at a flow rate of about $5 \mathrm{ml} / \mathrm{min}$. Electrical pulses $(300 \mu \mathrm{s})$ were applied through a pair of platinum electrodes. The stimulus frequency for twitch was $0.1 \mathrm{~Hz}$ and tetanus trains of $100 \mathrm{~Hz}$ were applied for $400 \mathrm{~ms}$. For the measurement of isometric tension, a single fiber was isolated and one tendinous end of the fiber was fixed with insect pins and the other was connected to a strain gauge (Fuji-Keisoku, TDS-101) and isometric tension was recorded on a Nihon Kohden recticorder (RJG-3024). The fiber length was adjusted to 1.3 times its slack length by the micromanipulator. For action potential measurements, small bundles containing fewer than 20 fibers were used. A conventional intracellular electrode technique was employed in conjunction with a Nihon Kohden MEZ-7101 amplifier. The microelectrodes had a resistance in the range of $10-30 \mathrm{M} \Omega$.

For measurements of the strength-duration relation for contraction, small bundles were used. Stimuli of variable duration (10 to 1,000 $\mu \mathrm{s})$ and strength, given from the pair of platinum electrodes which were placed close by the muscle bundle, were applied until a well-observable local contraction of a definite fiber could be detected under the microscope. Then stimulus strength was gradually decreased until the contraction was on the verge of disappearing. The measured strength was then defined as the contraction threshold. The results thus obtained were analyzed on the strength-duration relationship.

The Ringer solution had the following composition (mM): $\mathrm{NaCl}, 111.2 ; \mathrm{KCl}, 3$; $\mathrm{CaCl}_{2}, 2$; and HEPES, 5 ( $\mathrm{pH}$ 7.2). All solutions contained $10^{-5} \mathrm{~g} / \mathrm{ml} d$ tubocurarine. When the effects of $\mathrm{Ca}$ concentration were studied, $\mathrm{Ca}$ ions were 
simply added to or reduced from the Ringer solution. Similarly, the concentration of other divalent cations $(\mathrm{Ba}, \mathrm{Mg}, \mathrm{Ni}$ ) was changed in the modified Ringer solution which contained no $\mathrm{Ca}$ ions. All measurements were made at room temperature.

\section{RESULTS}

\section{Effects of exernal Ca concentration on the tension response}

The effects of extracellular Ca concentration of $0.5,2,4$, and $8 \mathrm{~mm}$ on both twitch and tetanus were examined. Figure 1 shows the effects of various external $\mathrm{Ca}$ concentrations on both twitch tension which was induced by a single stimulus of $0.1 \mathrm{~Hz}$ (A) and on tetanic tension induced by repetitive stimuli of $100 \mathrm{~Hz}$ for $400 \mathrm{~ms}$ (B). In both cases, the contractile force was decreased by increasing the $\mathrm{Ca}$ concentration from 0.5 to $8 \mathrm{mM}$. The results of five preparations are summarized in Fig. 2A and B. To examine whether the Ca release from the sarcoplasmic reticulum could also be affected by the procedure, the post-tetanic potentiation, expressed as a ratio of twitch height after tetanus (post twitch) to that before tetanus (pre twitch),

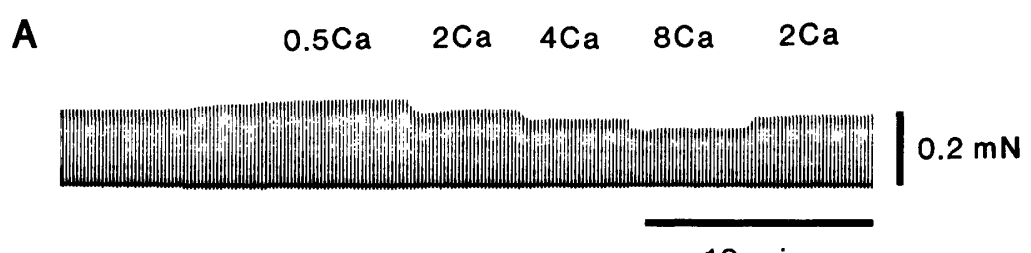

$10 \mathrm{~min}$

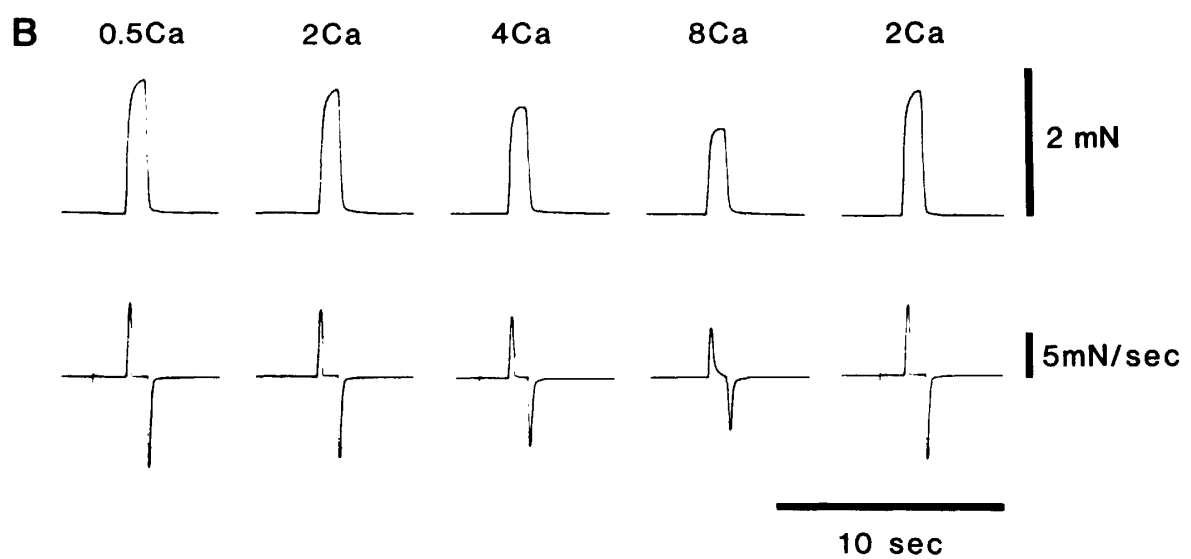

Fig. 1. Effects of the external Ca concentration on contractile responses. A: twitch tension in response to $0.1 \mathrm{~Hz}$ stimuli. The twitch tension in normal Ringer solution $(2 \mathrm{~mm} \mathrm{Ca})$ was potentiated by decreasing the concentration of $\mathrm{Ca}$ to $0.5 \mathrm{~mm}$. The concentration of $\mathrm{Ca}$ was increased stepwise. B: tetanic tension and its first derivative, in response to $100 \mathrm{~Hz}$ for $400 \mathrm{~ms}$. Tetani were induced every $5 \mathrm{~min}$. 

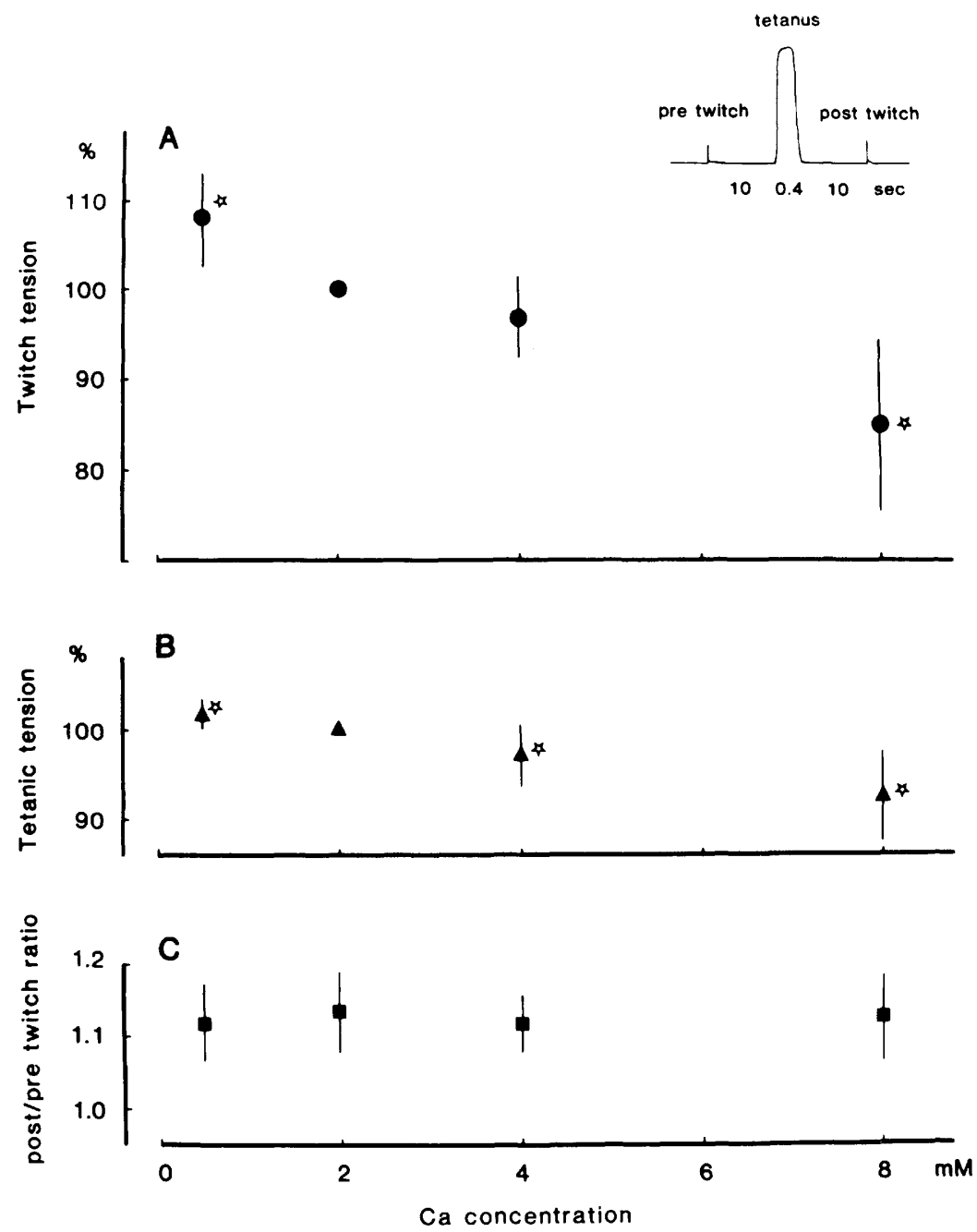

Fig. 2. Concentration-response relationship of Ca. The twitch tension (A) and the tetanic tension (B) are shown as \% of those in normal Ringer solution ( $2 \mathrm{~mm} \mathrm{Ca})$ and plotted against $\mathrm{Ca}$ concentration of bathing medium. Values indicate the mean \pm S.D. $(n=5)$. Asterisks indicate that the response is significantly different from that in normal solution $(2 \mathrm{~mm} \mathrm{Ca})$ with a paired $t$-test $(p<0.05)$. The post/pre twitch ratio $(C)$ is expressed by the ratio of the twitch tension which is induced $10 \mathrm{~s}$ after the tetanic stimulation against the twitch tension $10 \mathrm{~s}$ before the tetanus (above Fig. 2A).

was measured as shown in inset and showed in Fig. 2C. This parameter was almost independent of the $\mathrm{Ca}$ concentration, indicating that the post-tetanic potentiation was not effected by changing the external $\mathrm{Ca}$. 
A

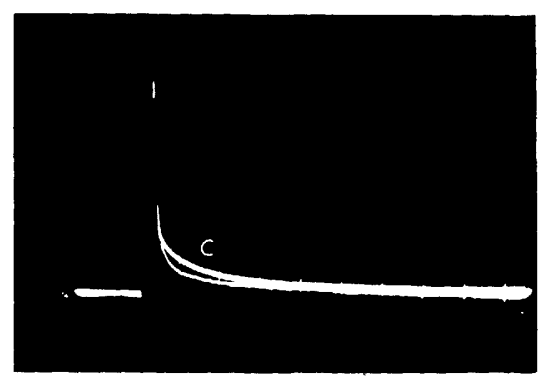

C

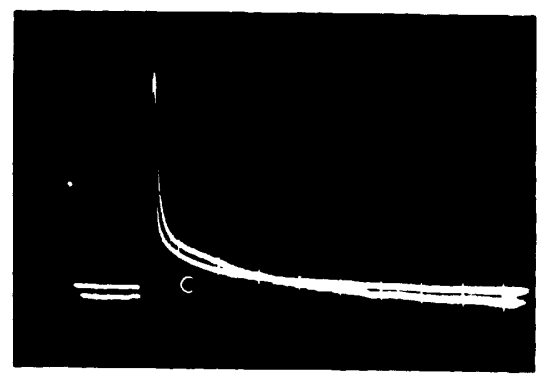

$50 \mathrm{msec}$
B

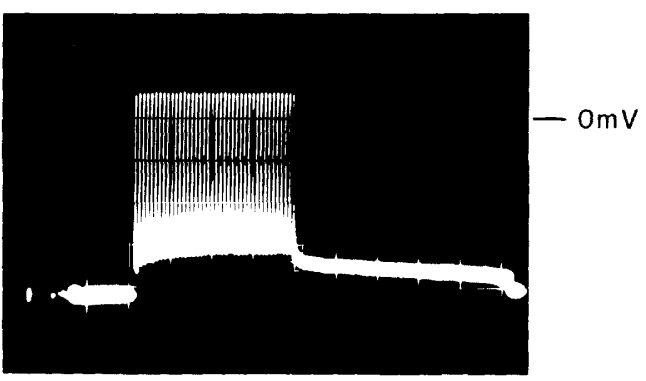

D

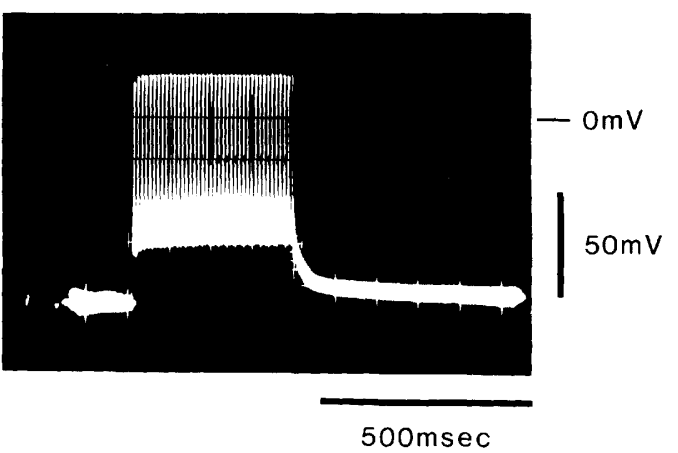

Fig. 3. Effects of $\mathrm{Ca}$ concentration on the action potential induced by the single and repetitive stimuli. Single stimulus was applied every 10 s for twitch and repetitive stimuli of $100 \mathrm{~Hz}$ every $5 \mathrm{~min}$ for tetanus. A: a superimposed record of action potential of control (c, $2 \mathrm{~mm} \mathrm{Ca}$ ) and that of $5 \mathrm{~min}$ after perfusion with low concentration of $\mathrm{Ca}(0.5 \mathrm{~mm})$. C: a superimposed record of control (c) and $5 \mathrm{~min}$ after perfusion of high concentration of Ca $(8 \mathrm{~mm})$. B and D are repetitive action potentials responding to tetanic stimuli in 0.5 and $8 \mathrm{~mm}$, respectively.

\section{Effects of $\mathrm{Ca}$ concentration on the action potential}

In Fig. 3 the action potential configuration was compared between low $(0.5 \mathrm{~mm})$ and high $(8 \mathrm{~mm}) \mathrm{Ca}$ concentration. The stimulus frequency was $0.1 \mathrm{~Hz}$ for twitch and $100 \mathrm{~Hz}$ for tetanus. Figure $3 \mathrm{~A}$ and $\mathrm{C}$ show the superimposed action potentials obtained in 0.5 and $2 \mathrm{~mm}, 2$ and $8 \mathrm{~mm}$, respectively. Figure $3 \mathrm{~B}$ and D represent the repetitive action potentials induced in 0.5 and $8 \mathrm{mM} \mathrm{Ca}$, respectively. In high concentration of $\mathrm{Ca}$, there is a slight hyperpolarization, an increase in the early afterpotential, and a decrease in the late afterpotential.

\section{Effects of $\mathrm{Ca}$ concentration on the strength-duration relationship}

One possible mechanism which might contribute to the decrease in twitch and tetanic tension by elevating extracellular $\mathrm{Ca}$ is the elevation of mechanical threshold (Lüttgau, 1963; Frankenhaeuser and Lännergren, 1967). 

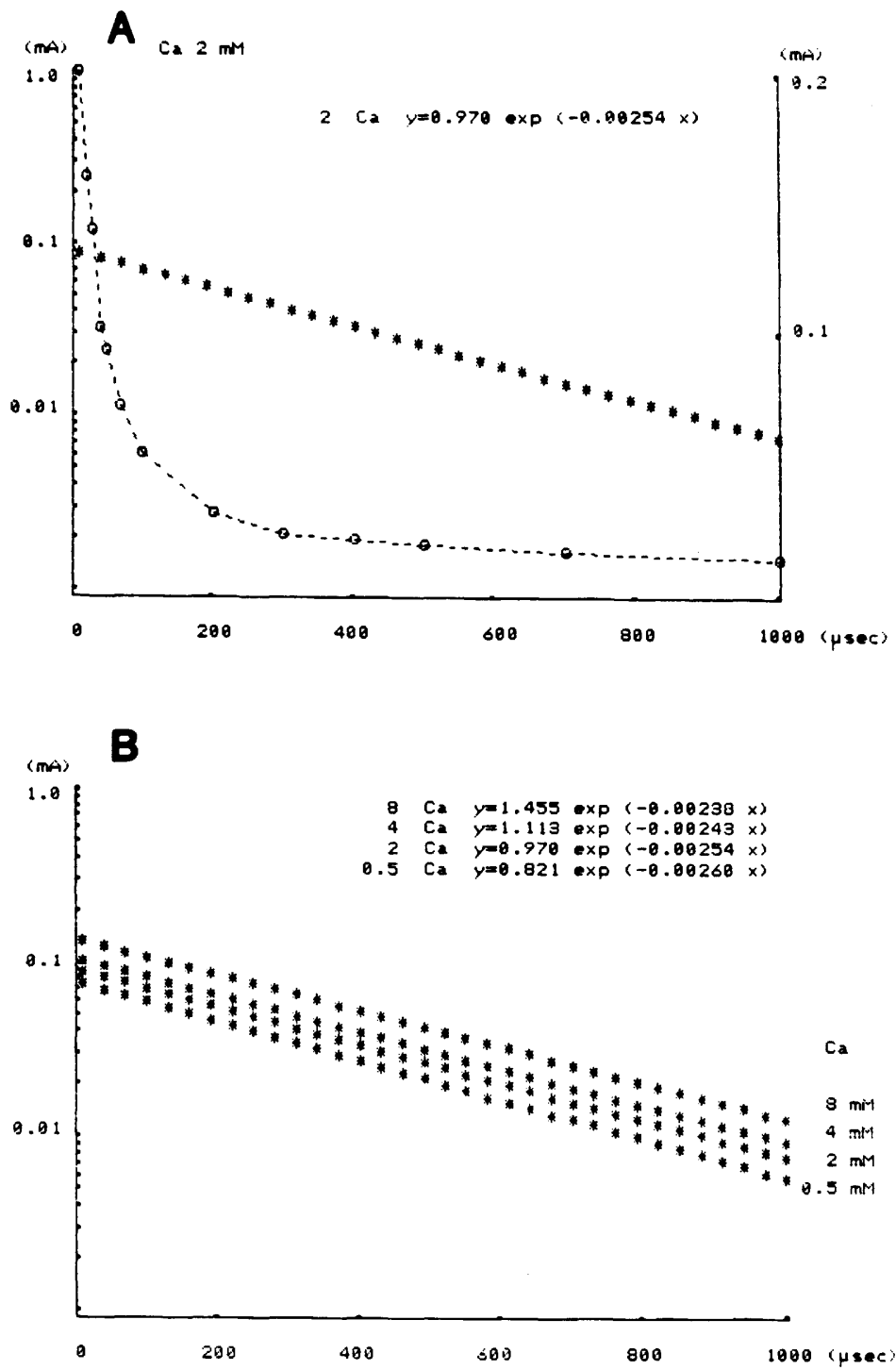

Fig. 4. Effects of external $\mathrm{Ca}$ concentration on the strength-duration relationship. Various pulse durations of 10,20,30,40,50,70,100, 200,300,400,500,700, and $1000 \mu$ s were used. For each pulse duration, current strength was first increased until a contraction could be detected. Then stimulus strength was gradually decreased until the contraction was on the verge of disappearing. The measured strength was then defined as the contraction threshold. A: the strength-duration relation obtained in normal Ringer solution. Open circles $(O)$ show the experimental data and asterisks $(*)$ show the same data obtained by curve fitting, the equation presented in the figure. $\mathrm{B}$ : the strength-duration curves for various $(0.5,2,4$, and $8 \mathrm{~mm}$ ) concentrations of $\mathrm{Ca}$. 


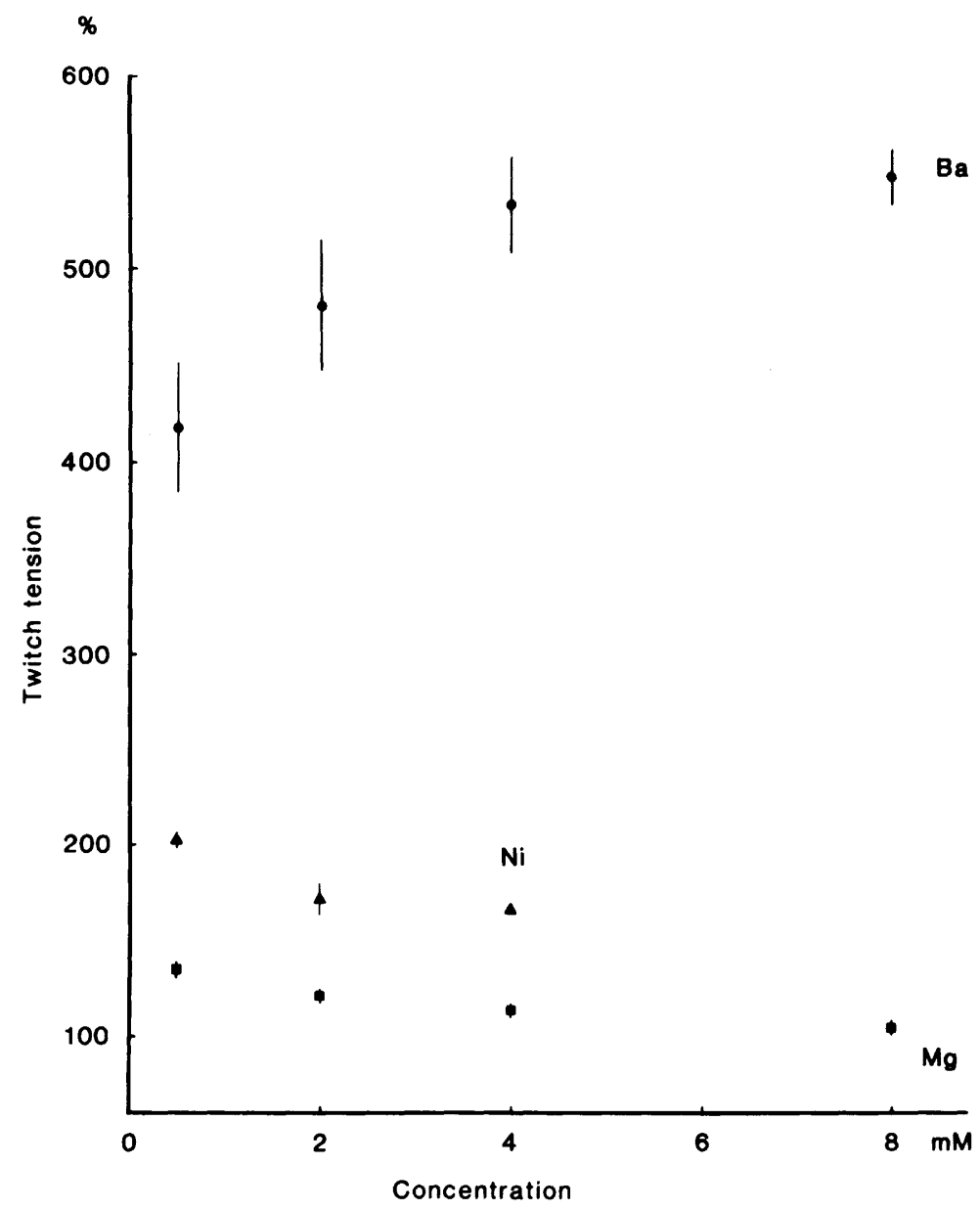

Fig. 5. Effects of the concentration of various divalent cations on twitch tension. The square marks represent the twitch tension in $\mathrm{Mg}$ Ringer solution. Triangles and circles show the results of $\mathrm{Ni}$ and $\mathrm{Ba}$, respectively. The solutions had no $\mathrm{Ca}$ ions. Each value is shown as \% of the force in normal Ringer solution. Vertical bars show the standard error (S.E.) of mean of five preparations.

The strength-duration relation for the contraction threshold was measured as described in the Methods and examined in various $\mathrm{Ca}$ concentrations (Fig. 4). Figure 4A shows the result obtained in normal Ringer solution. Open circles $(0)$ show the experimental data and asterisks $(\star)$ show the same data plotted on the logarithmic scale which was obtained by the equation of $y=0.970 \exp (-0.00254 x)$, based on the least square algorithm.

A similar measurement was done on various $\mathrm{Ca}$ concentrations. The line was shifted upward by increasing the Ca concentration; $y=0.821 \exp (-0.00260 x)$ for in 


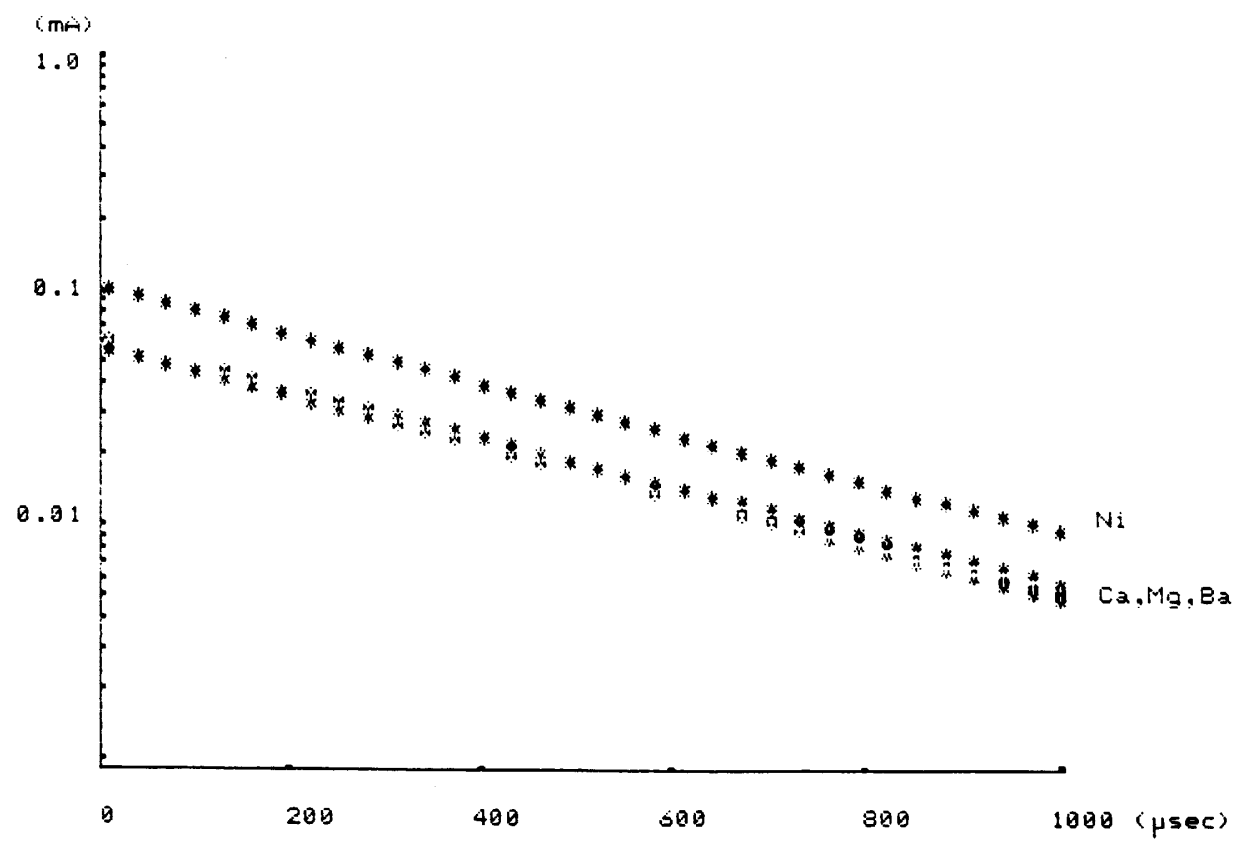

Fig. 6. The strength-duration relation in various divalent cations. The concentration of divalent cations used was $2 \mathrm{~mm}$. Various pulse durations of 10, 20, 30, 40, 50, 70, $100,200,300,400,500,700$, and $1000 \mu$ s were applied. The experimental procedure was the same as shown in Fig. 4. The data were treated by means of the least square algorithm and fitted to the following equations: $\mathrm{Mg}, y=0.664 \exp (-0.00256 x)$; $\mathrm{Ni}, \quad y=1.117 \exp (-0.00241 x) ; \quad \mathrm{Ba}, \quad y=0.616 \exp (-0.00241 x) ; \quad \mathrm{Ca}, \quad y=$ $0.657 \exp (-0.00239 x)$.

$0.5 \mathrm{~mm} \mathrm{Ca}, y=1.113 \exp (-0.00243 x)$ for $4 \mathrm{~mm} \mathrm{Ca}$, and $y=1.455 \exp (-0.00238 x)$ for $8 \mathrm{~mm} \mathrm{Ca}$.

4. Twitch tension in various concentrations of divalent cations

The steady state twitch tensions in response to $0.1 \mathrm{~Hz}$ stimuli in $0.5,2,4$, and $8 \mathrm{~mm}$ of divalent ions are summarized in Fig. 5 . Each value is presented as $\%$ relative to the value in normal Ringer solution ( $2 \mathrm{mM} \mathrm{Ca}$ ). In the case of $\mathrm{Mg}$ without $\mathrm{Ca}$, the higher the $\mathrm{Mg}$ concentration was, the smaller was the tension response. The twitch in $\mathrm{Mg}$ solution was larger than that in the solution containing only $\mathrm{Ca}$. Ni showed a similar effect as $\mathrm{Mg}$ although the extent of potentiation was larger than that of $\mathrm{Mg}$. The $8 \mathrm{~mm}$ Ni failed to induce any twitch response. In contrast, Ba showed marked potentiation and the potentiation was positively related to the Ba concentration. We investigated the effects of divalent cations on the tetanus and found that Ni showed an inhibitory effect, while $\mathrm{Mg}$ and $\mathrm{Ba}$ showed an opposite one (not shown). 


\section{Effects of divalent cations on the strength-duration relationship}

Figure 6 shows the strength-duration curve examined for various divalent cations. Each curve was obtained in the solution containing $2 \mathrm{~mm}$ of cation of either $\mathrm{Ca}, \mathrm{Mg}, \mathrm{Ba}$, and $\mathrm{Ni}$. The lines were obtained by the least square algotithm as shown in Fig. 4. Except for $\mathrm{Ni}$, other divalent cations exert almost the same result in the strength-duration relation: $y=0.657 \exp (-0.00239 x)$ for $\mathrm{Ca}, y=$ $0.664 \exp (-0.00256 x)$ for $\mathrm{Mg}$, and $y=0.616 \exp (-0.00241 x)$ for $\mathrm{Ba}$. The strengthduration relation for $\mathrm{Ni}$ clearly deviated and shifted upward: $y=$ $1.117 \exp (-0.00241 x)$.

\section{DISCUSSION}

Present investigation shows that the external concentration of divalent cations such as $\mathrm{Ca}, \mathrm{Mg}, \mathrm{Ni}$, and $\mathrm{Ba}$ critically affects the contractile responses of the fast skeletal muscle fiber. Except for Ba the extent of twitch potentiation was inversely related to the ion concentration. $\mathrm{Ba}$, which showed a marked twitch potentiation, exhibited a positive correlation with the ion concentration. Thus Ba behaves differently from the other three kinds of cations, although the causal nature of the twitch potentiation is not known. Moreover, the post-tetanic potentiation was not observed in Ba-containing solution (data not shown). It is known that Ba ions may carry charge through voltage-dependent Ca channels in several types of excitable cells (Sánchez and Stefani, 1978; Hagiwara and Byerly, 1981; Potreau and RAYMOND, 1980) and it has been proposed that $\mathrm{Ba}$ ions entering the muscle fiber may activate contraction by releasing $\mathrm{Ca}$ from the sarcoplasmic reticulum (POTREAU and RAYMOND, 1980) through the mechanism analogous to the Ca-induced $\mathrm{Ca}$ release (ENDO, 1977). By contrast, the post-tetanic potentiation was not affected by increasing the concentration of $\mathrm{Ca}$. This may indicate that, in the Ca-containing media, the overall intracellular $\mathrm{Ca}$ movement was not crucially modified by the procedure.

One possible mechanism which might contribute to the decrease in twitch and tetanic tension by increasing the extracellular divalent cations other than Ba would be the elevation of mechanical threshold (LÜTTGAU, 1963; FrankenHAEUSER and LÄNNERGREN, 1967). As to $\mathrm{Ca}$, the strength-duration curve shifted upward by increasing the concentration. A model can be considered where fixed charges on the outer surface of the tubular membrane generate a negative surface potential. Divalent cations are assumed to affect the surface potential either by binding to the fixed charges, or by screening off the fixed charges, thereby increasing the electric field within the membrane. Increase of the electric field may be as important as the elevation of mechanical threshold in the observed inhibition of twitch tension by elevated extracellualr $\mathrm{Ca}$ or other divalent cations.

Our analysis of the logarithmic plot of the strength-duration curve revealed that the curve consisted of single exponential component and that replacement of $\mathrm{Ba}$ or $\mathrm{Mg}$ ions behaved almost the same as $\mathrm{Ca}$, whereas $\mathrm{Ni}$ has a more potent effect. 
The same conclusion was also obtained in the presence of $\mathrm{Ca}$ (unpublished observation). The most potent effect of $\mathrm{Ni}$ on the surface charge has been reported in frog myelinated nerves (HILle et al., 1975).

Another mechanism for the inhibition due to $\mathrm{Ca}$ or other divalent cations would be a conduction failure of action potential, especially in the T-tubule. This possibility is unlikely because there exists no point of discontinuity in the tension curve plotted against the ionic concentration, except for $\mathrm{Ni}$ in higher concentrations. Action potential magnitude was well maintained during tetanus in both low and high $\mathrm{Ca}$ solutions. Thus the decline in tetanic tension is probably not related to any conduction failure. A slight hyperpolarization as well as prolongation for the action potential seen in high Ca medium may not be the cause for the twitch inhibition because the twitch height is assumed to positively correlate to the mechanically effective period, namely the action potential duration (SANDOW, 1965).

We thank Dr. Y. Ishida (Mitsubishi-Kasei Institute of Life Science) for valuable discussion. Thanks are also given to Dr. N. Fujishiro for helpful comments and to Miss K. Ogata for typing the manuscript. We are grateful to Miss E. Howell for improving the language.

\section{REFERENCES}

Bastian, J. and NaKajima, S. (1974) Action potential in the transverse tubules and its role in the activation of skeletal muscle. J. Gen. Physiol., 63: 257-278.

Bezanilla, F., Caputo, C., Gonzalez-Serratos, H., and Venosa, R. A. (1972) Sodium dependence of the inward spread of activation in isolated twitch muscle fibers of the frog. J. Physiol. (Lond.), 223: 507-523.

Caputo, D. and Dipolo, R. (1973) Ionic diffusion delays in the transverse tubules of frog twitch muscle fibers. J. Physiol. (Lond.), 229: 547-557.

CAPuto, C. and Bolanõs, P. (1979) Membrane potential, contractile activation and relaxation rates in voltage clamped short muscle fibres of the frog. J. Physiol. (Lond.), 289: $175-189$.

Costantin, L. L. (1970) The role of sodium currents in the radial spread of contraction in frog muscle fibers. J. Gen. Physiol., 55: 703-715.

Costantin, L. L. (1975) Contractile activation in skeletal muscle. Prog. Biophys. Mol. Biol., 29: 197-224.

Cota, G. and Stefani, E. (1981) Effects of external calcium reduction on the kinetics of potassium contractures in frog twitch muscle fibres. J. Physiol. (Lond.), 317: 303-316.

DörRSCHEIDT-KäFER, M. (1976) The action of $\mathrm{Ca}^{2+}, \mathrm{Mg}^{2+}$, and $\mathrm{H}^{+}$on the contraction threshold of frog skeletal muscle. Pflügers Arch., 362: 33-41.

Endo, M. (1977) Calcium release from the sarcoplasmic reticulum. Physiol. Rev., 57: $71-108$.

FranKENHAEUSER, B. and LÄNNERGREN, J. (1967) The effect of calcium on the mechanical response of single twitch muscle fibers of Xenopus laevis. Acta Physiol. Scand., 69: 242254.

Graf, F. and Schatzmann, H. J. (1984) Some effects of removal of external calcium on pig 
striated muscle. J. Physiol. (Lond.), 349: 1-13.

Hagiwara, S. and Byerly, L. (1981) Calcium channel. Annu. Rev. Neurosci., 4: 69-125.

Hatae, J. and Kawata, H. (1985) Effects of divalent cations on the excitation-contraction coupling in skeletal muscle fibers. J. Physiol. Soc. Jpn., 47: 513.

Hille, B., Woodgull, A. M., and Shapiro, B. I. (1975) Negative surface charge near sodium channels of nerve: Divalent ions, monovalent ions, and $\mathrm{pH}$. Philos. Trans. $\mathrm{R}$. Soc. Lond. B, 270: 301-318.

Hodgkin, A. L. and Horowicz, P. (1960) Potassium contractures in single muscle fibres. J. Physiol. (Lond.), 153: 386-403.

LÜrTGAU, H. C. (1963) The action of calcium ion on potassium contractures of single muscle fibers. J. Physiol. (Lond.), 168: 679-697.

LÜtTGAU, H. C. and SPIECKER, W. (1979) The effects of calcium deprivation upon mechanical and electrophysiological parameters in skeletal muscle fibres of the frog. $J$. Physiol. (Lond.), 296: 411-429.

Potreau, D. and Raymond, G. (1980) Slow inward calcium current and contraction of frog single muscle fibers. J. Physiol. (Lond.), 303: 91-109.

SÁNCHEZ, J. A. and STEFANI, E. (1978) Inward calcium current in twitch muscle fibres of the frog. J. Physiol. (Lond.), 283, 197-209.

SAndow, A. (1965) Role of the action potential in excitation contraction coupling. Fed. Proc, 24: 1116-1123. 